\title{
Development of a Simple and Low-cost Smartphone Gimbal with MPU-6050 Sensor
}

\author{
Arif Ainur Rafiq ${ }^{1}$, Wahid Nur Rohman ${ }^{2}$ Sugeng Dwi Riyanto ${ }^{3}$ \\ 1,2,3 Department of Electrical Engineering, Politeknik Negeri Cilacap, Cilacap, Indonesia \\ Email: arifainurrafiq@politeknikcilacap.ac.id
}

\begin{abstract}
This paper discusses about design and development of gimbal smartphone, which are made to be simple and less money consuming by utilizing microcontroller and MPU 6050 sensor. Recently, the development of videography and image processing is inseparable from the rapid advance in smartphone technology. One of the most popular features is camera. Hand movements and shocks cause fewer maximum results. To improve the quality of camera captures and video, it is necessary to have a stabilizer for camera position. Thus, it is expected that the outcomes of this paper are able to give contribution for cheap gimbal smartphone. Design and implementation of gimbal uses acrylic as the material, with 5 mm of thickness. This MPU 6050 sensor is optimized to detect sway in axis $\mathrm{X}, \mathrm{Y}$, and $\mathrm{Z}$ or roll, pitch, and yaw. Gyroscope and accelerometer provide input to the microcontroller, which will process for output on 3 servomotors that function to maintain the camera's position at a specified set point. The results show that MPU 6050 sensor can response angle reading error of $1.34^{\circ}$ of roll, $0.25^{\circ}$ of pitch, and $0^{\circ} 78^{\circ}$ of yaw. Error in maximum servomotor movement is $1.5^{\circ}$. Thus, it can be concluded that gimbal can work optimally with less money consuming as well as low error. It is expected that the next research will add other suitable and accurate control, that is, PID or fuzzy.
\end{abstract}

\section{Keywords—gimbal, MPU-6050 sensor, servo motor}

\section{INTRODUCTION}

The main aim of this paper is to develop stabilized camera control system which is used in number of applications such as photography. The camera control system is supporting using a mechanical system known as gimbal system. In photograpy, taking pictures and videos can be done through several media. As the recent development of technology, especially in science, everything can be carried out easily and fast. The most important factors to know the quality of movie are camera and its supporting devices, because hand movement while taking pictures, that is called camera shake, causes undesirable image blur. The objects present in unstable environment are arranged in stable position using this mechanical device [1], [2]. Thus, camera and capture devices continue to improve. The supporting devices that are recently used to take video is gimbal. Control of camera can be feasible by manual control but it is complex and tedious since it requires separate operator to control it [3]. Gimbal is a camera movement controller tool in axis $\mathrm{x}, \mathrm{y}$, and $\mathrm{z}$.

Gimbal functions as a tool to maintain camera angle in a particular direction. Gimbal is very compatible to be used in a system commonly used on camera. The system is called Pan Tilt Zoom (PTZ) [4], which is a pan to control yaw axis of camera. Tilt is camera tilt control in the form of pitch and roll axes. Zoom is a magnification control of image on the camera. In PTZ system, gimbal is used to move the camera on pitch, roll, and yaw angle so that the camera can maintain its angle [5], [6].

Many people still use tripod to record video. However, it is important to know that tripod is only used to help us hold a camera, not to stabilize the video. Thus, it is more effective to use gimbal, which is not only useful to record video, but also to stabilize the picture. To examine camera motions, the simplest method is to shoot a pint light source [7]. To prevent or reduce the camera shake in smartphone, the gimbal for image stabilizer has been developed. The common architecture consists of built-in gyro sensors that identify the hand movement and the movement cancellation mechanism that precisely shifts the optical axis or image sensing device to compensate for the camera motion [8], [9].

\section{METHODS}

The method used to develop gimbal smartphone consists of designing system, designing hardware, and implementing the whole system.

\section{A. Designing System}

System consisted of accelerometer sensor and gyroscope MPU6050 to detect object's orientation over the gravity. Data processing and decision making used Arduino Uno. Actuator used three servomotors.

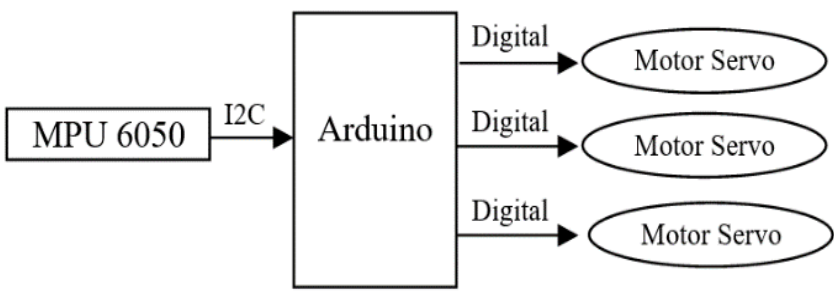

Fig. 1. Block Diagram System

The working principle of this tool started from the input in the form of MPU6050 sensor, which was a gyroscope and accelerometer used to read the tilt or shake. Input data from the sensor was processed by Arduino Uno as microcontroller to match the method used, and data from the microcontroller was used to drive the servomotor as the output of the device to stabilize the camcorder. Smartphone functioned as an object to be stabilized and a media of picture or video recorder.

\section{IMU Sensor}

The gimbal used to control is 3-axis gimbal which consist of IMU Sensor [10]. Inertial Measurement Unit (IMU) is a sensor used to measure speed, orientation, and gravity through 
accelerometer and gyroscope. IMU is often used in aircraft system. IMU which be applied in many navigation systems such as for mobile platform [11], spin-stabilized of sounding rocket [12], autonomous of vehicle navigation [13], and personal navigator [14] uses either the accelerometer or the gyroscope or both as the main component.

The first component of IMU is accelerometer sensor. This sensor is used to measure the acceleration of an object by carrying out an integral acceleration of the object over time. The next component of IMU Sensor is gyro sensor. The sensor works by detecting motion according to gravity, or in other words, detecting the user's movement. Gyroscope has an output in the form of angular velocity from 3 axis direction, namely $\mathrm{x}$ axis/phi angle (right and left) of y axis/angle theta (top and bottom), and $\mathrm{z}$ axis/psi angle (front and back) [15], [16], and [17].

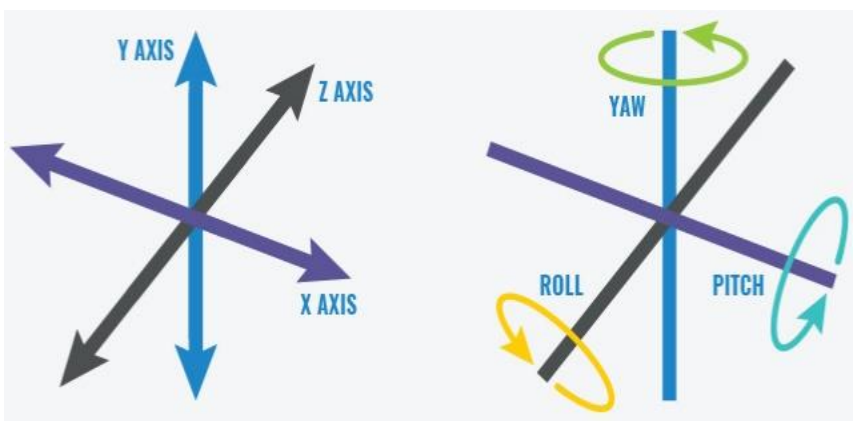

Fig. 2. Six degrees of freedom movement

Sensor used in this design is MPU 6050. It is available in the market with affordable price. MPU 6050 sensor is one of sensors that use the basic principles of IMU sensor [18]. The register setting on MPU 6050 is carried out by microcontroller with I2C communication [19], [20].

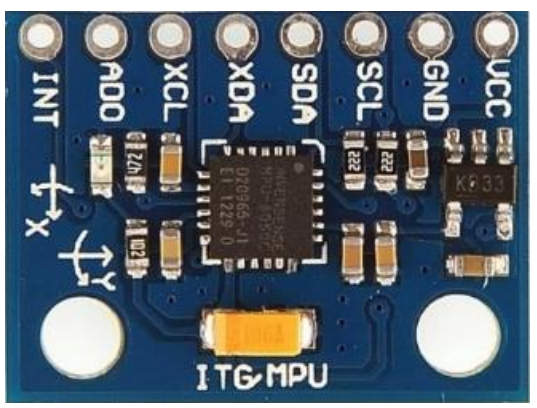

Fig. 3. MPU 6050 Sensor

\section{Arduino Uno}

Arduino is a microcontroller board based on ATmega328 [21], [22]. Arduino Uno can be activated via a USB connection or with an external power supply [23]. The power source is selected automatically [24]. This microcomputer has 14 digitals I/O port (six of them can provide the PWM outputs), 6 analog I/O ports, a reset switch and a ISP download [25]. In this article, Arduino functions as a controller of all components and commands given.

\section{Servo Motor}

Servo mechanism is the principle work of DC motor which has 3 wires and maximum angle of $180^{\circ}$ can be rotated [26]. Servo motor is a motor that works based on the work procedure of closed loop, so that the rotation angle of the servomotor can be adjusted [27]. Servo motor angle can be adjusted by using Pulse Width Modulation (PWM) input. The magnitude of torque used in MG996R servomotor type is $9.40 \mathrm{~kg}-\mathrm{cm} \mathrm{[28]}$. That size of torque would be enough to rotate the shaft of the servomotor. Controlling servomotor is different from regular DC motor. To control servomotor, it is necessary to use PWM (Pulse Width Modulation) [29].

\section{Electronic Design}

In electronics design, 3 servo motors were connected to Arduino Uno which received input from MPU6050 sensor. Input in the form of tilt or shock used gyroscope and accelerometer. The smartphone was placed on a camera mount so it did not fall while being used.

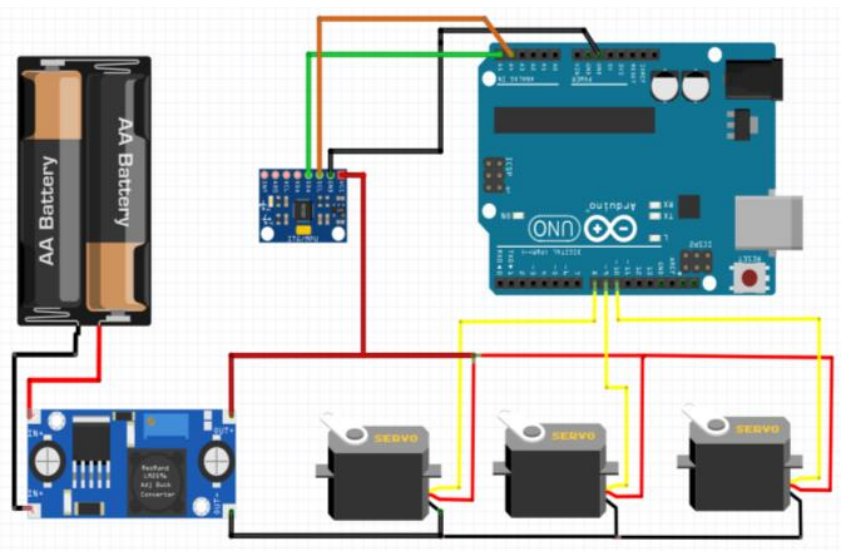

Fig. 4. Schematic Diagram

This stabilizer used a servomotor connected to one another so that it was able to determine the yaw, pitch, and roll angles according to the placement of the motor. The results of data from gyroscope sensor and accelerometer were used to drive the servomotor to the axis $\mathrm{x}, \mathrm{y}$, and $\mathrm{z}$ to adjust the balance so that the smartphone remains in the set point condition that has been adjusted in Arduino Uno microcontroller program. The battery assembled in series produced a voltage of 7.4 volts, and it was reduced into 5 volts by a buck converter to be distributed to servomotors, Arduino, and MPU-6050.

\section{B. System Flow Chart}

Flowchart of the tool working procedure is shown in Figure 5. A flowchart is a diagram with graphical that express the flow of an algorithm and a process that displays the step of the system proposed.

The set point of this tool was adjusted, and after then, the sensor performed the initial position reading. If the position has been matched with the set point, the motor will be silent. Meanwhile, if the position has not been matched, it will read again to find out whether it exceeds the set point. If it exceeds the set point, the pitch and roll motor will move clockwise while the yaw motor will remain at the set point. If it is less than the set point then the counter will move clockwise. If it has been matched, the motor will be silent. 


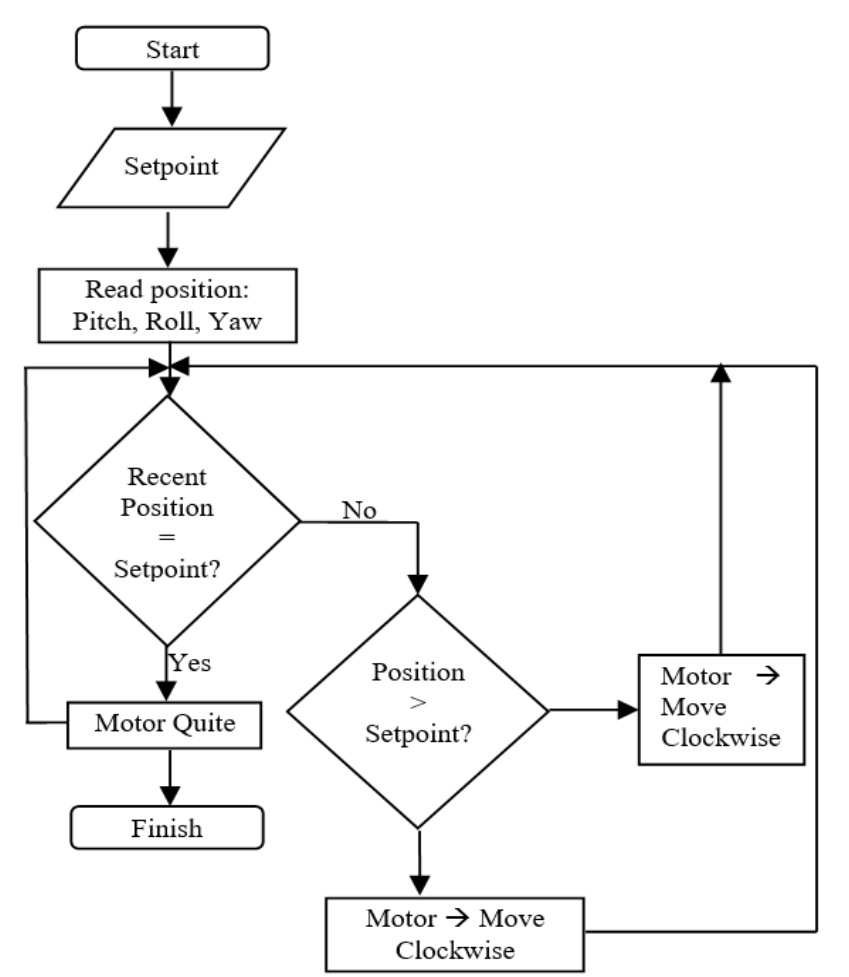

Fig. 5. System Flowchart

\section{System Hardware}

In this hardware design, AutoCAD software is used to provide detailed image and precise measurements. Component placement is also a factor in compatibility between design and implementation. In its implementation, the material used was acrylic, with a size of $5 \mathrm{~mm}$, so it was strong enough to support the burden of a smartphone.

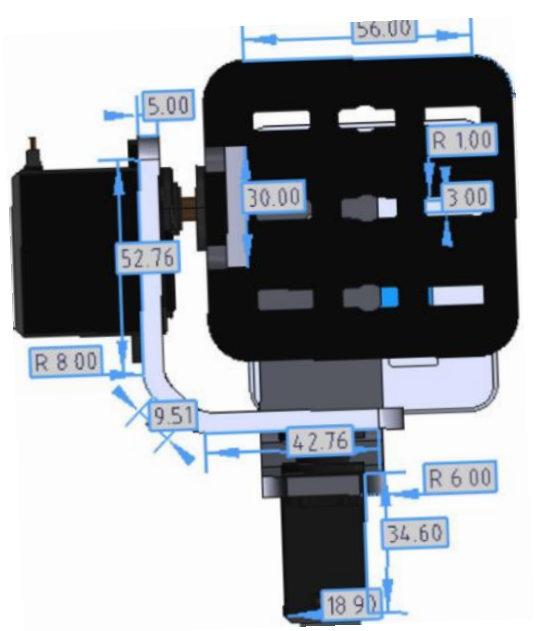

Fig. 6. Mechanical design of the tool from the side view

In this design, it consists of 3 MG996 servo motors for the 3 -axis control and a base on which the MPU6050 sensor, the Arduino and the battery will be placed.

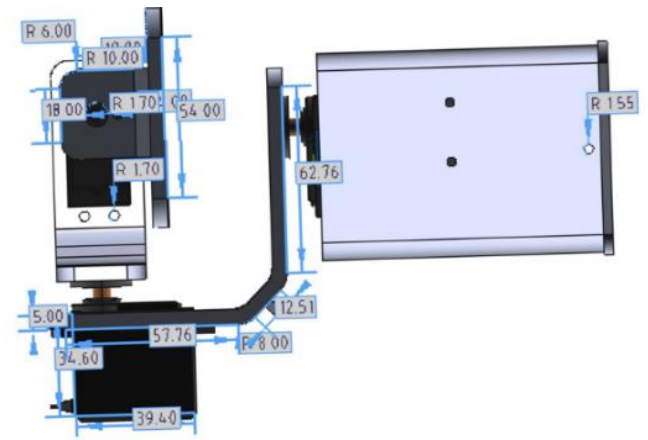

Fig. 7. Mechanical design of the tool from the back view

In the figure of mechanical design, each motor will be connected to each other by the mouth so that they can move as in line with the axis, roll, and pitch. Position of the motor is also adjusted in accordance with the design commonly used by people.

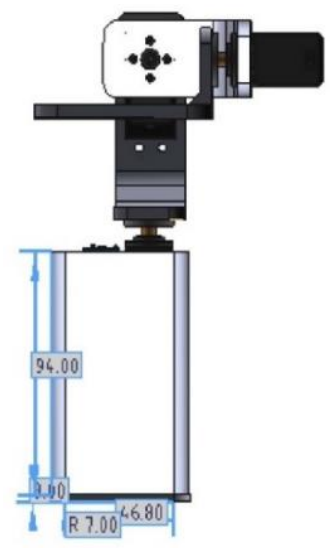

Fig. 8. Mechanical design of the tool from the front view

\section{RESULT AND DISCUSSION}

The tool testing method starts from testing several parts including servomotor testing, MPU6050 sensor, and system response. After that, the angle data is taken from gyroscope sensor and accelerometer, in which the data is used to drive the servomotor.

\section{A. Sensor Testing}

Sensor testing is conducted to each axis, namely pitch, roll, and yaw. The results of each axis can be seen in Table 1, Table 2, Table 3, and Figure 5.

TABLE 1. THE RESULT OF ROLL ANGLE TESTING

\begin{tabular}{|c|c|c|c|}
\hline No & Angle $\left(^{\circ}\right)$ & Data of Sensor Reading $\left(^{\circ}\right)$ & Error $\left(^{\circ}\right)$ \\
\hline 1 & 0 & 0 & 0 \\
\hline 2 & 30 & 31.55 & 1.55 \\
\hline 3 & 45 & 46.67 & 1.67 \\
\hline 4 & 60 & 62.31 & 2.31 \\
\hline 5 & 90 & 91.20 & 1.20 \\
\hline \multicolumn{3}{|c|}{ Average } \\
\hline
\end{tabular}

Table 1 present that the sensor has been able to show the data of angle and to detect the tilt position with the average of error for the roll of 1.34. The smallest error value is 1.20 at the angle $90^{\circ}$. And the highest error is 2.31 at the angle $60^{\circ}$.

TABLE 2. THE RESULT OF PITCH ANGLE TESTING 


\begin{tabular}{|c|c|c|c|}
\hline 1 & 0 & 0 & 0 \\
\hline 2 & 30 & 29.66 & 0.34 \\
\hline 3 & 45 & 45.72 & 0.72 \\
\hline 4 & 60 & 60.58 & 0.58 \\
\hline 5 & 90 & 89.89 & 0.11 \\
\hline \multicolumn{3}{|c|}{ Average } & 0.35 \\
\hline
\end{tabular}

Based on the result on Table 2, it can be analysed that the sensor has been able to show the data of angle and to detect the tilt position with the average of error for the pitch of 0.35 . The smallest error value is 0.11 at the angle $90^{\circ}$. And the highest error is 0.72 at the angle $45^{\circ}$.

TABLE 3. THE RESULT OF YAW ANGLE TESTING

\begin{tabular}{|c|c|c|c|}
\hline No & Angle $\left({ }^{\circ}\right)$ & Data of Sensor Reading $\left({ }^{\circ}\right)$ & Error $\left(^{\circ}\right)$ \\
\hline 1 & 0 & 0 & 0 \\
\hline 2 & 30 & 30.5 & 0.5 \\
\hline 3 & 45 & 46.78 & 1.78 \\
\hline 4 & 60 & 60.54 & 0.54 \\
\hline 5 & 90 & 91.12 & 1.12 \\
\hline \multicolumn{3}{|c|}{ Average } & 0.78 \\
\hline
\end{tabular}

Based on the result on Table 3, it present that the sensor has been able to show the data of angle and to detect the tilt position with the average of error for the yaw of 0.78 . The smallest error value is 0 . at the angle $30^{\circ}$. And the highest error is 1.78 at the angle $45^{\circ}$.

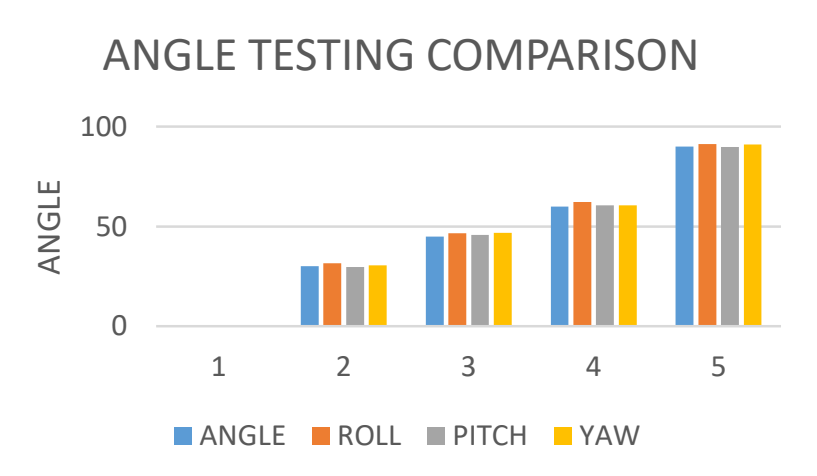

Fig. 9. Graph of the results of sensor testing comparison

Based on the graph in Figure 9, it is seen that the sensor has been able to detect the tilt angle properly to all axes. The reliability value is used to determine the level of consistency of measurements repeatedly with the same conditions or circumstances. The smaller the reliability value produced, the more stable the measurement level [30]. The validity value is influenced by the deviation value.

\section{B. Servo Motor Testing}

Servo motor testing aims to find out whether servomotor can move according to the turning angle as an input. This test uses Arduino test as a microcontroller to provide input on the servomotor. After conducting the experiment above, a table is made to identify and to make a decision whether the servomotor functions properly.

The results of servomotor testing can be seen in Table 4 . Based on the results of servomotor, it is seen that servo motor can do the angle movement in line with the set point, with the average value is 1.32 degree. This value is still in a normal range in its use.

TABLE 4. THE RESULT OF YAW ANGLE TESTING

\begin{tabular}{|c|c|c|c|}
\hline No & Angle $\left(^{\circ}\right)$ & Data of Servo Angel $\left(^{\circ}\right)$ & Error $\left(^{\circ}\right)$ \\
\hline 1 & 0 & 0 & 0 \\
\hline 2 & 45 & 46 & 2 \\
\hline 3 & 60 & 60.2 & 1.2 \\
\hline 4 & 90 & 90.5 & 0.5 \\
\hline \multicolumn{2}{|c|}{ Average } & 1.32 \\
\hline
\end{tabular}

\section{System Mechanism Testing}

System mechanism testing is carried out by monitoring the movement of the tool when it moves to the right and left. Based on the test, it is seen that smartphone can maintain its orientation although the tool is tilted to the right and left. Small error still occurs in this testing because of not using controller to produce smoother output on the servomotor during its implementation.

Assembling the gimbal was quite easy but it must be carefully for connecting one other. It started with installing the Yaw servo and secured it to the base. Next, using the same method to install the Roll and Pitch servo. The parts are specifically designed to easily fit the MG996R servos.

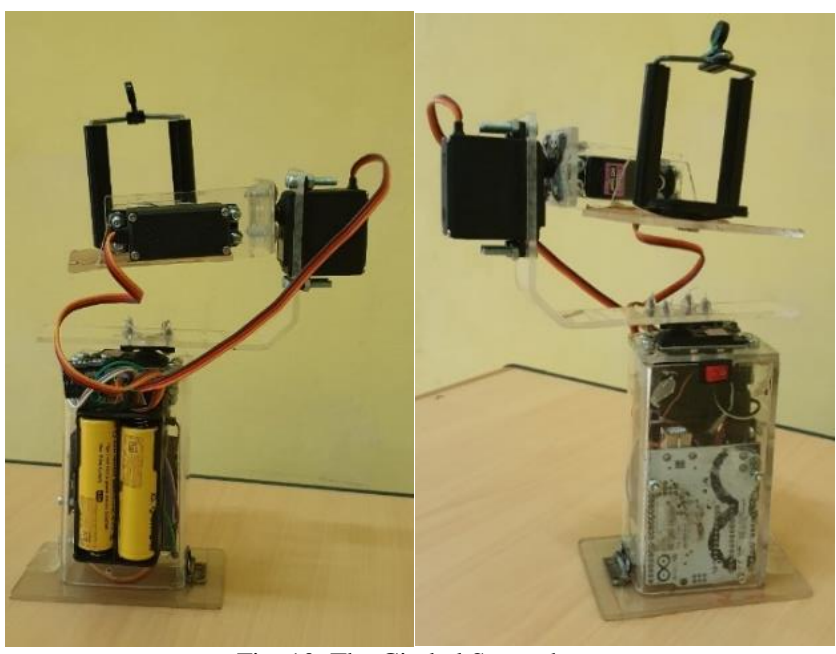

Fig. 10. The Gimbal Smartphone

From the Figure 10, we can see that for powering the gimbal, it used 2 Li-ion Batteries which it placed in the battery holder. The $2 \mathrm{Li}$-ion batteries will produce around $7.4 \mathrm{Vt}$, but it need $5 \mathrm{~V}$ for powering the Arduino and the servos. That's why it used a buck converter which will convert $7.4 \mathrm{~V}$ to $5 \mathrm{~V}$ in order to make it suitable with the voltage references.

Overall, with a cost of no more than Rp. 400.000, we can make a gimbal smartphone that are simple and inexpensive but reliable according to their function. With this the selfbalancing platform or the Arduino gimbal is done and it works well as expected.

\section{CONCLUSION}

After going through the process of designing, testing, and analysis based on the results that have been done, it can be concluded that the 3 servomotors used can stabilize the smartphone with a maximum error rate of $2.31^{\circ}$ on the roll 
angle reading. The use of acrylic material is sufficient to support a smartphone load up to a size of 6.3". This article can provide an easy, cheap, and simple alternative to produce an aid for photography lovers with accurate results. In the next research, it is recommended to use a type of BLDC motor to get the smooth movement.

\section{REFERENCES}

[1] R. J. Rajesh, Kavitha P," Camera Gimbal Stabilization Using Cnventional PID Controler and Evolutionary Algorithm," IEEE International Conference on Computer, Communication and Control (IC4), September 2015.

[2] Tiimus K and Tamre M, "Camera Gimbal "Control System for Unmanned Platforms", 7th International DAAAM Baltic Conference "INDUSTRIAL ENGINEERING", Tallinn, Estonia, 22-24 April 2010.

[3] [3] Taki Shiino, Kazuo Kawada, Toru Yamamoto, Manabu Komichi and Takafumi Nishioka, "Gimbals Control with the Camera for Aerial Photography in RC Helicopter" International Conference on Control, Automation and Systems in COEX, Seoul, Korea, 2008 Oct. 14-17, 2008.

[4] A. Silverstein F. Xiao and J. Farrell, "Camera-motion and effective spatial resolution," Proceedings of International Congress of Imaging Science, pp. 33-36, May 2006.

[5] Ma Jie and Xu Qinbei, "Four-axis gimbal system application based on gimbal self-adaptation adjustment," Proceeding of the $34^{\text {th }}$ Chinesse Control Conference, pp. 8866-8871, July 2015.

[6] V. Gergely, Avoiding Gimbal Lock, Computer graphics world, 2009(32):10.

[7] M.G. Song. W.C. Kim N.P. Park Y.P. Park H. Choi, J.P. Kim and K.S. Park, "Effects of motion of an imaging system and optical image stabilizer on the modulation transfer function," Optics Express, vol. 16, no. 25, pp. 21132-21141, Dec. 2008.

[8] K. Nishi and R. Ogino, "3d camera-shake measurement and analysis," Proceedings of ICME, pp. 1271-1274, July 2007.

[9] H.S. Lee S.C. Park and S.W. Lee, "Qualitative estimation of camera motion parameters from the linear composition of optical flow,” Pattern Recognition, vol. 37, no. 4, pp. 767-779, April 2004.

[10] Mohammad Abdul Rahman Al-Mashhadani, "Optimal and PID Controller for Controlling Camera's Position in Unmanned Aerial Vehicles", International Journal of Information Technology, Modelling and Computing (IJITMC), Vol.1, No.4, November 2013.

[11] Batista, Pedro., C. Silvestre, Paulo Oliveira, and Bruno Cardeira, Accelerometer Calibration and Dynamic Bias and Gravity Estimation: Analysis, Design, and Experimental Evaluation, IEEE Transactions on Control System Technology, Vol. 19, No. 5, September 2011, pp. $1128-1137$.

[12] Bekkeng, Jan K., Calibration of Novel MEMS Inertian Reference Unit, IEEE Transactions on Instrumentation and Measurement, Vol. 58, No. 6, June 2009, pp. 1967 - 1974.

[13] Hossein, Tehrani Nik Nejad., Seiichi Mita, and Han Long, MultiSensor Data Fusion for Autonomous Vehicle Navigation through Adaptive Particle Filter, IEEE Intelligent Vehicles Symposium, San Diego, CA, USA June 21-24, 2010, pp. 752 - 759.

[14] Moafipoor, S., D.A. Grejner-Brzezinska, and C. K. Toth, Multisensor Personal Navigator Supported by Adaptive Knowledge
Based System: Performance Assessment, IEEE/ION Position, Location, and Navigation System, Monterey, CA, USA, 5-8 May 2008, pp. $129-140$.

[15] Datasheet MPU-6050, "MPU-6000 and MPU-6050 product specification," 2018.

[16] M. F. Alwi, M. Rivai, and Suwito., "Perancangan Sistem Stabilisasi Kamera Tiga Sumbu Dengan Metode Kontrol Fuzzy Untuk Mobile Surveillance Robot," J. Tek. ITS

[17] D. Rodríguez-Martín, A. Carlos Pérez-López, J. C. Samà, and A. Català, "A Wearable Inertial Measurement Unit for Long-Term Monitoring in the Dependency Care Area," Sensors, vol. 13, no. 12, 2013.

[18] Wahyudi and Ngatelan, "Design of Multi-sensor IMU for Land Vehicle," Proceeding of $20152^{\text {nd }}$ Int. Conference on Information Technology, Computer and Electrical Engineering, Indonesia, pp. 271-274, October 2015.

[19] M. H. Daware and A. S. Patil, "Implementation of I2C Bus Protocol on FPGA," Int. J. Curr. Eng. Sci. Res., vol. 2015, 2015.

[20] H. Ardiansyah, M. Rivai, and L. Prihadi Eka Nurabdi, "Train arrival warning system at railroad crossing using accelerometer sensor and neural network," in AIP Conference Proceedings, 2018.

[21] Sonny. K, Kantohe. K, Waroh. A," Light Intensity Control Prototype Design Using Arduino Uno," Proceeding 2018 International Conference on Applied Science and Technology (ICAST), pp. 563-566, October 2018.

[22] Adiono T, Tandiawan B, Fuada S, Muttaqin R, Fathany MY, Adijarto W, Harimurti S. Prototyping design of IR remote controller for smart home applications. InRegion 10 Conference, TENCON IEEE. 2017; 1304-1308.

[23] Adiono T, Putra RV, Fathany MY, Lawu BL, Afifah K, Santriaji MH, Fuada S. Rapid prototyping methodology of lightweight electronic drivers for smart home appliances. International Journal of Electrical and Computer Engineering (IJECE). 2016; 6(5):2114-2124.

[24] Kamaruddin N, Rahman AW, Halim KI, Noh MH. Driver Behaviour State Recognition based on Speech. TELKOMNIKA Telecommunication, Computing, Electronics and Control. 2018;16(2): 852-861.

[25] Bolun Zneg, Jianbo Zhang, Lang Chen and Yao Wang, 'Selfbalancing car based on Arduino Uno R3," IEEE $3^{\text {rd }}$ Advanced Informataion Technology, Electronic and Automation Control Conference, IAEAC 2018, pp. 1939-1943, 2018.

[26] M. J. Fadhil, R.A. Fayadh, MK. Wali, "Design and Implementation of Smart Electronic Solar Tracker based on Arduino," TELKOMNIKA Telecommunication, Computing, Electronics and Control. 2019;17(5): 2486-2496.

[27] Wang M, Lu C. Design and implementation of a sun tracker with a dual-axis single motor for an optical sensor-based photovoltaic system. Sensors. 2013; 13(3): 3157-3168.

[28] Ji Lanlong, Cao Rongmin, Zhou Huixing and Hou Zhongsheng, "Servo system design and Implementation based on position and speed control for the linear motor,' Proceeding of the $34^{\text {th }}$ Chinese Control Conference Hangzhou, pp. 4223-4227, July 2015.

[29] Datasheet Motor Servo, "Motor Servo MG996R datasheet."

[30] De la Escalera, A.; Armingol, J.M. Automatic Chessboard Detection for Intrinsic and Extrinsic Camera Parameter Calibration. Sensors 2010, 10, 2027-2044. 